\title{
Cell mediated Immunity Against Three Eye Muscle Antigens and Correla- tion with Eye Signs in Patients with Transient and Chronic Thyroiditis
}

\author{
Bao Nguyen ${ }^{1}$, Bamini Gopinath ${ }^{2}$, Gary Ma ${ }^{3}$, Bernard Champion ${ }^{1}$ and Jack R. Wall*,1 \\ ${ }^{1}$ Department of Medicine, the University of Sydney, Nepean Hospital, PO Box 63, Penrith, New South Wales 2751, \\ Australia \\ ${ }^{2}$ Centre for Vision Research, the University of Sydney, Westmead Hospital, Westmead, NSW 2145, Australia \\ ${ }^{3}$ Laboratory of Endocrine Research ICPMR, Westmead Hospital, Sydney, NSW, Australia
}

\begin{abstract}
Background: Mild eye signs, especially itchiness and grittiness of the eyelids and upper eyelid retraction (UER), are found in about 25\% of patients with Hashimoto's thyroiditis (HT) in whom antibodies against calsequestrin and flavoprotein (Fp) are often detected. The role of $\mathrm{T}$ lymphocyte reactivity against eye muscle antigens in patients with thyroiditis has not been investigated.

Methods: We studied peripheral blood T lymphocyte reactivity against calsequestrin, Flavoprotein (Fp) and G2s in patients with transient (sub acute and silent) thyroiditis (TT) and HT, determined in a standard proliferation assay. Reactivity was expressed as stimulation index (SI) and correlated with signs of ophthalmopathy and upper eyelid disease, assessed as; NOSPECS classes, clinical activity score (CAS) and upper eyelid retraction (UER).

Results: Positive lymphocyte proliferation to calsequestrin was demonstrated in $71 \%$ of TT patients all of whom had mild ophthalmopathy and this was significantly increased compared to normal control subjects. The prevalences of positive T cell reactivity to calsequestrin was also significantly increased in HT patients (38\%) compared to the controls, all of whom had upper eyelid disease. Three out of 7 patients with upper eyelid disease (6 of the patients with TT or HT and one other patient with Graves' disease) taken as a separate group, demonstrated significant $\mathrm{T}$ lymphocyte sensitisation to calsequestrin. TSH-receptor antibodies were detected in only one TT patient and one patient with upper eyelid disease.

Interpretation: The development of ophthalmopathy and/or eyelid retraction (in the absence of TSH-r antibodies and Graves' hyperthyroidism) in TT patients is closely associated with an autoimmune reaction against calsequestrin. These findings support the notion that ophthalmopathy and upper eyelid inflammation and dysfunction are independent autoimmune disorders not necessarily linked with thyroid autoimmunity and that $\mathrm{T}$ cell reactivity plays a role.
\end{abstract}

Keywords: Thyroiditis, ophthalmopathy, T-cells, lymphocyte proliferation, eye muscle antigens, eyelid retraction.

\section{INTRODUCTION}

Periorbital oedema, exophthalmos, upper eyelid retraction and impaired vision occur in approximately $50 \%$ of patients with Graves' hyperthyroidism [1-3]. Generally mild eye changes, usually manifest as chronic upper eyelid retraction (UER), also occur in about 25\% of patients with Hashimoto's thyroiditis (HT) [4] and less often in patients with transient (sub acute, silent) thyroiditis (TT) [5]. Hence, this autoimmune disorder of the orbital tissue is best termed thyroid associated ophthalmopathy (TAO) or thyroid eye disease. The pathogenesis of the ophthalmopathy is not well understood but one popular hypothesis is that autoimmunity against antigens in the extraocular muscles, the levator palpebrae superioris (LPS) muscle in the upper eyelids and the orbital connective tissue and fat, is initiated by immune cross reactivity against a thyroid and orbital shared antigen

*Address correspondence to this author at the Department of Medicine, University of Sydney, Nepean Hospital, PO Box 61, Penrith NSW 2751, Australia; Tel: +61 (02) 4734 2613; Fax: +61 (02) 4734 2614;

Email: jackw@med.usyd.edu.au such as the TSH-receptor (TSH-r) [6, 7]. Over the last several years our studies have focused on the role of autoimmunity against the calcium binding skeletal muscle protein calsequestrin; we have shown that calsequestrin antibodies are closely associated with eye muscle damage in patients with TAO and UER $[5,8,9]$.

"Thyroiditis" comprises a group of inflammatory thyroid disorders [10]. Namely; sub acute thyroiditis (SAT), silent thyroiditis (ST) and Hashimoto's thyroiditis (HT). The former two are forms of transient destructive thyroiditis while HT is chronic and progressive [10,11]. There is evidence that the ophthalmopathy and upper eyelid disease associated with destructive thyroiditis may occur independently of hyperthyroidism and TSH-r antibodies [12]. A recent case report demonstrated euthyroid Graves' ophthalmopathy 3 years after proven SAT in association with a positive extraocular muscle antibody test in the absence of thyroid autoimmunity, thyroid antibodies and TSH-r antibodies [13] supports this hypothesis. An earlier study performed by our group showed high levels of antibodies against calsequestrin and flavoprotein (Fp), and signs of ophthalmopathy or domi- 
nant chronic upper eyelid disease, in the absence of TSH-r antibodies, in TT and HT patients [14], supporting the notion that thyroid related orbital and eyelid autoimmunity may occur independently of Graves' disease and TSH-r antibodies.

We have studied the role of $\mathrm{T}$ lymphocyte sensitization to eye muscle antigens in patients with Graves' disease [15] but not in patients with transient and progressive thyroiditis. The $\mathrm{T}$ lymphocytes are thought to have a key role in the pathogenesis of TAO, particularly in the early stages, as far more $\mathrm{T}$ cells infiltrating affected extraocular muscles are seen in the earlier stages than the later, more chronic, stages of eye disease $[16,17]$. Here, we have studied the nature and significance of cell mediated immunity to three eye muscle antigens in well characterised patients with transient or chronic thyroiditis, correlating with eye and eyelid signs.

\section{METHODS}

\section{Clinical Subjects}

The patients were recruited from the Thyroid Clinic at Nepean Hospital, Australia. The demographics, history, thyroid function, thyroid antibody titres at diagnosis and nature and severity of the ophthalmopathy and eyelid disease are summarised in Table $\mathbf{1}$. Briefly, we studied;
1) Four patients with ST and 3 patients with SAT, all females, aged 20 - 75 (mean age $43 \mathrm{yr}$ ) taken as the "transient thyroiditis (TT)" group. Six of these patients had mild orbitopathy, 3 of whom had upper eyelid disease. Only one patient with ST had active UER in the absence of other signs of orbitopathy.

2) Eight patients with Hashimoto's thyroiditis, one male and 7 females aged 23 - 75 (mean age 53 yr) two of whom had congestive ophthalmopathy and UER while one patient had eye muscle dysfunction and congestive changes, but no eyelid signs. Three HT patients had UER in the absence of other signs of orbitopathy. The remaining two patients did not have any eye or eyelid signs.

3) Sixteen age and sex matched normal subjects, 4 males and 12 females aged 28 - 54 (mean age 43 yr) as healthy controls.

4) Six of the patients with TT or HT and one other patient, a female aged 63 with Graves' disease, as an "isolated UER” group.

5) Twenty two patients with Graves' ophthalmopathy, 4 males and 18 females aged 24 - 77 as historical positive ophthalmopathy control group, tested at the same time as the study groups.

Table 1. Demographical Data, Biochemical and Immunological Characteristics and Treatment of Patients with Transient Thyroiditis, Chronic (Hashimoto's) Thyroiditis, Isolated Upper Eyelid Disease and Graves' Ophthalmopathy, and Healthy Controls, Tested for Cell Mediated Immunity Against Three Eye Muscle Antigens

\begin{tabular}{|c|c|c|c|c|c|c|c|c|c|c|c|c|c|}
\hline \multirow[b]{2}{*}{ GROUP } & \multirow[b]{2}{*}{$\begin{array}{c}\text { Age } \\
\text { Range } \\
\text { (yr) }\end{array}$} & \multirow[b]{2}{*}{$\begin{array}{c}\text { Sex } \\
(\mathbf{F} / \mathbf{M})\end{array}$} & \multirow[b]{2}{*}{$\begin{array}{c}\text { Nunery } \\
\text { Type (no.) }\end{array}$} & \multirow[b]{2}{*}{$\begin{array}{l}\text { CAS } \\
(0-10)\end{array}$} & \multirow[b]{2}{*}{ UER $^{\mathrm{c}}$} & \multirow[b]{2}{*}{$\begin{array}{c}\text { Mean } \pm \text { SD } \\
\text { Serum } T_{4}{ }^{d} \\
{ }^{\text {Normal }} \\
\text { Range; 9-19 } \\
\text { pmol/L) }\end{array}$} & \multirow[b]{2}{*}{$\begin{array}{c}\text { Mean } \pm \text { SD } \\
\text { Serum TSH } \\
{ }^{\mathrm{e}} \\
\text { Rormal } \\
\text { mange; } 0.3-3.5 \\
\text { mIU/L)) }\end{array}$} & \multicolumn{3}{|c|}{$\begin{array}{l}\text { Positive Thyroid Anti- } \\
\text { bodies }(\%)^{a}\end{array}$} & \multicolumn{3}{|c|}{$\begin{array}{l}\text { Treatment at Time of } \\
\text { Testing (no.) }{ }^{\mathbf{b}}\end{array}$} \\
\hline & & & & & & & & TPO & Tg & TSH-r & $\mathbf{L}-\mathbf{T}_{4}$ & ATD & Nil \\
\hline $\begin{array}{l}\text { Transient thyroiditis } \\
(n=7)\end{array}$ & $26-55$ & $7 / 0$ & $\begin{array}{l}0(1) \\
1(6)\end{array}$ & $\begin{array}{c}0(2) \\
1(1) \\
2(2) \\
3-4(2)\end{array}$ & 4 & $14.2 \pm 1.8$ & $2.0 \pm 2.4$ & 28.6 & 0.0 & 14.3 & - & - & 7 \\
\hline $\begin{array}{l}\text { Hashimoto's thyroiditis } \\
(n=8)\end{array}$ & $23-78$ & $7 / 1$ & $\begin{array}{l}0(5) \\
1(2) \\
2(1)\end{array}$ & $\begin{array}{l}0(5) \\
2(3)\end{array}$ & 5 & $13.9 \pm 3.0$ & $1.9 \pm 0.9$ & 75.0 & 25.0 & NT & 2 & - & 6 \\
\hline $\begin{array}{l}\text { Isolated Upper eyelid } \\
\text { retraction }{ }^{\mathrm{f}}(n=7)\end{array}$ & $26-78$ & $7 / 0$ & $\begin{array}{l}0(6) \\
1(1)\end{array}$ & $\begin{array}{l}0(6) \\
2(1)\end{array}$ & 7 & $12.7 \pm 2.4$ & $1.4 \pm 1.0$ & 71.4 & 42.9 & NT & - & 1 & 6 \\
\hline Healthy controls $(n=16)$ & $28-54$ & $12 / 4$ & - & - & - & $\mathrm{NT}^{\mathrm{g}}$ & NT & NT & NT & NT & - & - & - \\
\hline
\end{tabular}

${ }^{\mathrm{a}} \mathrm{TPO}=$ thyroid peroxidase (normal range; 0-35 IU/m), TG = thyroglobulin (normal range; 0-40 IU/m), TSH-r = TSH-receptor (normal range; 0-2 IU/L)

${ }^{\mathrm{b}}$ Number of patients who were treated with thyroxin (L-T4) supplementation, anti-thyroidal drugs (ATD) or who were receiving no treatment at the time of testing (Nil)

${ }^{\mathrm{c}} \mathrm{UER}=$ upper eyelid retraction

${ }^{\mathrm{d}} \mathrm{T}_{4}=$ Free thyroxin

${ }^{\mathrm{e}} \mathrm{TSH}=$ thyroid stimulating hormone

${ }^{\mathrm{f}}$ One patient with TT, 5 with HT and one with Graves’ disease

${ }^{\mathrm{g}} \mathrm{NT}=$ not tested 
The diagnoses of the various disorders were based on standard clinical criteria and confirmed by thyroid function testing, thyroid ultrasonography and immunological tests. The grade, severity and activity of any ophthalmopathy were classified as; 1 ) Nunery types 1 (without restrictive myopathy) or 2 (with restrictive myopathy) [18] (2) as the clinical activity score (CAS) (0-10) of Mourits et al. [19] which is a measure of disease activity (but not severity) 3) Werner's NOSPECS class [20] and 4) the upper eyelid margin-reflex distance (MRD) which is the distance between the centre of the pupillary light reflex and the upper eyelid margin with the eye in primary gaze, as a measure of upper eyelid retraction (UER). An MRD of $>5 \mathrm{~mm}$, which correlates with a score of $\geq+$ using our clinical assessment protocol, is taken as significant UER. Isolated UER was not considered "ophthalmopathy" and was analysed separately. The degree of exophthalmos (mm) was measured using a Hertel exophthalmometer. Local Ethical Committee approval was received for the study and informed consent of participating subjects was obtained.

\section{Lymphocyte Proliferation Assay}

Peripheral blood mononuclear cells (PBMC) were isolated from heparinised blood using a standard FicollHypaque (Amersham Biosciences) gradient centrifugation method, as described in an earlier publication from our laboratory [15]. The cells were washed three times with RPMI1640 (Gibco, BRL, USA) supplemented with 5\% heat inactivated foetal bovine serum. PBMC were enumerated using a standard haemocytometer before suspending in RPMI-1640, supplemented with $2 \mathrm{nM}$ L-glutamine, 100U/ml of penicillin, $100 \mu \mathrm{g} / \mathrm{ml}$ of streptomycin (Pen-Strep) and $10 \%$ heat inactivated FBS, RPMI-10\%, at a concentration of $5.0 \times 10^{5}$ cells per ml. The optimal concentration of PBMC response to the $\mathrm{T}$ cell mitogen Concanavalin A (ConA) was determined in preliminary assays using PBMC from a normal subject. We tested a series of cell concentrations over the range $1.25 \mathrm{x}$ $10^{4}-5 \times 10^{5}$ cells $/ \mathrm{ml}$. The optimal concentration that gave the lowest background (non-stimulated) absorbance and maximal response to ConA was $5 \times 10^{5}$ cells/ml, which was used in all subsequent assays.

Lymphocyte proliferation response to Fp, calsequestrin and G2s was measured by a conventional colorimetric bromodeoxyuridine (BrdU) uptake (Roche Molecular Biochemicals). BrdU, which is a thymidine analog, is a non-radioactive alternative to tritiated thymidine. PBMC were cultured on 96 flat-bottomed culture plates. G2s fusion protein was purified using a pFLAG ATS E. coli expression system as described previously [20], human recombinant Fp was kindly donated by Dr. Brian Ackrell (UCSF, CA) and highly purified rabbit skeletal muscle calsequestrin, which has 97\% homology with human calsequestrin, was supplied by Dr Nicole Beard (Canberra, Australia). The optimal antigen concentrations that resulted in maximal antigen-induced proliferation were determined in preliminary experiments. These were; 17.4 $\mu \mathrm{g} / \mathrm{ml}$ for calsequestrin, $17.4 \mu \mathrm{g} / \mathrm{ml}$ for Fp and $15 \mu \mathrm{g} / \mathrm{ml}$ for G2s, which were used in subsequent proliferation assays.

All cultures were performed in duplicate and incubation time was 6 days. On day five of the assay, BrdU was added to the cultures as recommended by the manufacturer and cells were then re-incubated for another 24 hours at $37^{\circ} \mathrm{C}$. The amount of newly synthesised BrdU-DNA was estimated the following day using an ELISA reader (BioRad) at 450 $\mathrm{nm}$, the absorbance values correlating directly to the amount of DNA synthesis. Results were expressed as stimulation index (SI), calculated; mean absorbance of test sample duplicate (antigen added) - background (no cells)/mean absorbance of negative control (no antigen) - background (no cells). A SI of $>$ mean +2 SD for normals, the "upper limit of normal” namely; 1.6 for calsequestrin, 2.0 for Fp, 3.2 for G2s and 3.7 for Con A, was taken as a positive test. From Trypan Blue exclusion tests, over $90 \%$ of the cultured mononuclear cells were alive at the end of the culture.

\section{Other Tests}

Plasma free thyroxin (fT4), thyroid stimulating hormone (TSH) and serum thyroid peroxidase (TPO) and thyroglobulin (TG) antibodies were measured by Barratt \& Smith Pathology, Sydney, Australia using commercial kits (the Immulite method) according to the manufacturers' instructions. The normal range was $0-40 \mathrm{IU} / \mathrm{ml}$ for thyroglobulin antibodies and 0-35 IU/ml for thyroid peroxidase antibodies and the cut-off points $40 \mathrm{IU} / \mathrm{ml}$ and $30 \mathrm{IU} / \mathrm{ml}$, respectively. TSH-r antibodies, determined as TSH binding inhibiting immunoglobulin (TBII), were measured at the Pathology Department of Westmead Hospital, Sydney, Australia by one of us (GM) using commercial kits according to the manufacturer's instructions. The normal range was $0-2 \mathrm{IU} / \mathrm{L}$ and the cut off point 2 IU/L.

\section{Statistical Analysis}

Statistical analysis was carried out using SigmaStat (version 2.0; Jandel Co., San Rafael, CA USA). The prevalences of positive tests in patient groups were compared statistically using $\chi^{2}$ test or the Fishers exact test (for five or less expected observations in one or more cells). Mean SI ( \pm SE) for groups were compared using One Way Analysis of Variance (ANOVA) with a Bonferroni correction. In all tests, a $p$-value of $<0.05$ was taken as significant.

\section{RESULTS}

We tested PBMC from 7 patients with TT and 8 patients with HT, included as a chronic thyroiditis control group, for lymphocyte proliferation to three eye muscle antigens. In addition, we tested at 7 patients with isolated upper eyelid disease (eyelid lag and/or retraction) in the absence of other signs of orbitopathy, as a separate group namely; 6 of the patients with TT or HT and one other patient, aged 63, with Graves' disease. The results are summarised in Table 2 and Fig. (1). Mean $( \pm S E)$ SI responses to calsequestrin were significantly greater in TT $(3.5 \pm 1.2)$ and UER patient groups $(1.8 \pm 0.4)$ compared to normal controls $(0.6 \pm 0.1$, p $<0.05$, Fig. 1). However, significant differences in lymphocyte proliferation responses to Fp and G2s between patient and control groups were not demonstrated $(p=N S)$. There were also no significant differences in mean SI $( \pm \mathrm{SE})$ response to the 3 eye muscle antigens in patients with HT compared to normal controls ( $p=N S$, Fig. 1). Overall, positive lymphocyte proliferation to calsequestrin, taken as an SI $>1.6$, was found in $71 \%$ of patients with TT all of whom had mild orbitopathy 
and 2 of whom also had UER, which was significantly greater than in normal controls $(\mathrm{p}<0.01$, Table 2$)$. Significant differences in prevalences of positive lymphocyte response to calsequestrin were also observed between normal controls and patients with HT (38\%, p < 0.05), all of whom had UER and 2 of whom had other signs of orbitopathy (Table 2). Forty-three \% of patients with isolated upper eyelid disease demonstrated positive $\mathrm{T}$ cell reactivity to calsequestrin, which was significantly greater than in the control group ( $\mathrm{p}<0.01)$. As a positive ophthalmopathy control group we included 22 patients with Graves' ophthalmopathy, of whom 59\% demonstrated positive $\mathrm{T}$ cell responses to calsequestrin, $18 \%$ to G2s and $14 \%$ to Fp (from; Nguyen et al. ref. 15). Significant differences in prevalences of patients showing positive $\mathrm{T}$ cell reactivity to Fp and G2s compared to age and sex matched controls, were not observed $(\mathrm{p}=\mathrm{NS}$, Table 2). Finally, prevalences of positive response to the $T$ cell mitogen Con A were increased compared to normals in all 4 groups of patients, although the differences were not significant $\left(\chi^{2}\right.$ test $\left.\mathrm{p}=\mathrm{NS}\right)$ (Table 2$)$.

\section{DISCUSSION}

Several eye muscle antigens have been identified in our studies over the past 20 years [21]. These include; the, D protein G2s, a small fragment of the large protein FOXP1 (Human Genome Project) [22], flavoprotein (Fp) [23] and calsequestrin, a calcium binding protein expressed in the sarcolemmal and other cell membranes in all skeletal muscle cells. Antibodies against calsequestrin are closely associated with ac-

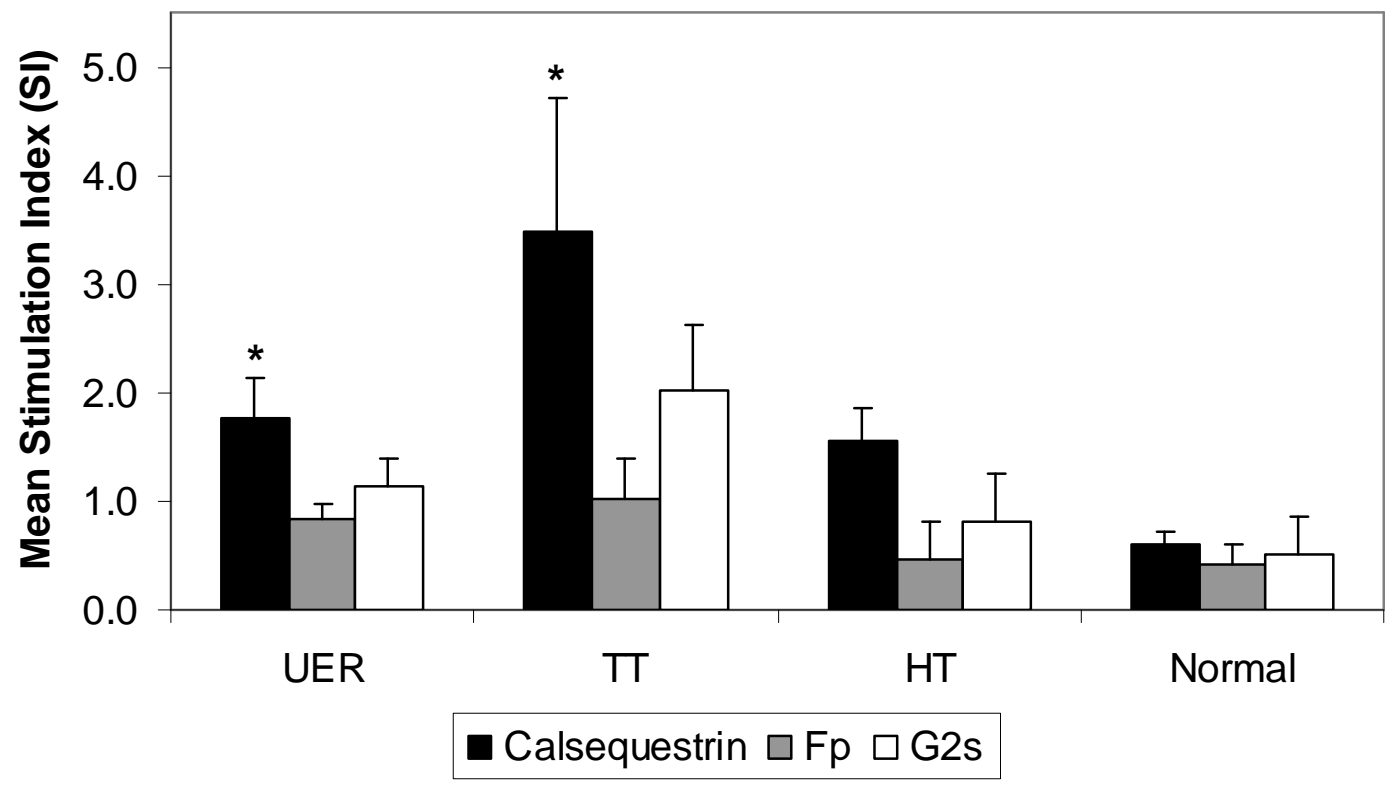

Fig. (1). Peripheral blood T lymphocyte reactivity to calsequestrin, Fp and G2s in patients with transient (sub acute and silent) thyroiditis (TT), Hashimoto's thyroiditis (HT), isolated upper eyelid retraction (UER) and normal controls. Results are expressed as mean ( \pm SE) SI (Yaxis). ${ }^{*} \mathrm{P}<0.05$ versus normal controls.

Table 2. Prevalences of Positive T Lymphocyte Reactivity Against Three Eye Muscle Antigens in Patient Patients with Transient Thyroiditis, Chronic (Hashimoto's) Thyroiditis, Isolated Upper Eyelid Retraction and Healthy Control Subjects and Normal Controls

\begin{tabular}{|c|c|c|c|c|}
\hline Group & \multicolumn{4}{|c|}{ Numbers (\%) giving positive T-cell reactivity against; } \\
\hline Hashimoto's thyroiditis (n=8) & $3(37.5)^{d}$ & $0(0.0)$ & $0(0.0)$ & $6(75.0)$ \\
\hline Isolated upper eyelid retraction $(n=7)$ & $3(42.9)^{d}$ & $0(0.0)$ & $0(0.0)$ & $5(71.4)$ \\
\hline Normal controls $(n=16)$ & $0(0.0)$ & $1(6.3)$ & $0(0.0)$ & $7(43.8)$ \\
\hline
\end{tabular}

${ }^{\mathrm{a}} \mathrm{Fp}=$ Flavoprotein

${ }^{\mathrm{b}} \mathrm{Con} \mathrm{A}=$ Concanavalin $\mathrm{A}$

${ }^{c} \mathrm{p}<0.01$ vs normal controls

${ }^{d} \mathrm{p}<0.05$ vs normal controls

${ }^{\mathrm{e}}$ From Nguyen et al., ref 15 
tive ophthalmopathy and eye muscle inflammation in patients with Graves' hyperthyroidism and less often Hashimoto's thyroiditis [4] and transient thyroiditis [14], but usually negative in patients with other thyroid disorders and other autoimmune disorders [5, 8, 9]. In 2001 Porter et al. [24] demonstrated by micro-array technology that calsequestrin was expressed 4.7 times more in eye muscle than other skeletal muscle, providing a possible explanation for the localisation of a skeletal muscle reaction in the orbit. Cardiac calsequestrin (CASQ2) is encoded by a different gene but the two proteins share 60\% homology; antibodies targeting CASQ2 do not cross react with calsequestrin [25]. Another orbital antigen of interest is the fibroblast cell membrane protein collagen XIII. Antibodies targeting collagen XIII are linked to the congestive ophthalmopathy subtype of TED $[14,26]$.

In a recent study [14] we reported that mild ophthalmopathy was often found in patients with SAT or ST, in the absence of TSH-r antibodies or Graves' hyperthyroidism, but associated with one or more eye muscle antibodies. To further explore the relationship between the development of eye/eyelid signs in thyroiditis patients and immune responses to eye muscle antigens, we tested PBMC from patients with transient and chronic thyroiditis for lymphocyte proliferation to calsequestrin, Fp and G2s. To summarise the main findings, positive lymphocyte proliferation to one or more eye muscle antigens was detected in $71 \%$ of patients with TT, $38 \%$ with HT and in $43 \%$ of patients with isolated UER. Overall, the prevalences of positive reactivity to the 3 antigens were similar to those in patients with thyroiditis or isolated UER. Significant differences in mean SI responses to calsequestrin only were found in both transient thyroiditis and UER patient groups compared to normal controls. The eye signs were, in all but one case, mild but definite and symptoms tended to be more severe than signs and severe progressive ophthalmopathy was not seen in any patient. Overall there was a fairly close relationship between eye and eyelid signs and $\mathrm{T}$ cell reactivity to calsequestrin, but not G2s or Fp. The increased T lymphocyte responses to Con A in all 4 patient groups may reflect a general $\mathrm{T}$ cell activation in the context of transient thyroiditis and chronic thyroid autoimmunity.

In our recent studies we have shown that calsequestrin antibodies are sensitive and specific markers of extra ocular muscle inflammation and damage, not only in patients with Graves' disease [8, 9] but also in those with Hashimoto's thyroiditis [4] and transient (sub acute, silent) thyroiditis [14]. In addition, we have recently shown that calsequestrin may be a target of $\mathrm{T}$ lymphocyte-mediated immune responses in patients with Graves' ophthalmopathy [25]. While antibodies against the eye muscle antigens flavoprotein (Fp) and G2s are also linked to ophthalmopathy they are less specific and sensitive markers of eye muscle damage [3, 9, 20].

The role of the TSH-r in the pathogenesis of ophthalmopathy and eyelid disease needs to be questioned as TSH-r antibodies are not generally detected in patients with thyroiditis [14] and levels of TSH-r antibodies do not always correlate with clinical features of eye disease, including signs of eye muscle damage in patients with Graves' disease [12]. This suggests that the ophthalmopathy and UER associated with thyroid disorders, in particular thyroiditis, may be more closely related to a cellular and humoral immune response to calsequestrin than to the TSH-r antigen. Hence, the relationship between thyroid autoimmunity and ophthalmopathy needs to be re-assessed by measuring, calsequestrin, collagen XIII and TSH-r antibodies in a large cohort of patients with Hashimoto's thyroiditis in a long term prospective study, correlating with risk factors for ophthalmopathy such as smoking, severity of the thyroid autoimmune process, iodine availability and stress. While the logical way to further study a role of cell mediated immunity against eye muscle antigens and collagen XIII in thyroid autoimmunity would be to test T lymphocytes from the orbits of patients with eye signs, correlating $\mathrm{T}$ lymphocyte response with clinical eye signs and eye muscle and collagen XIII antibodies, such T cells are not readily available. We would carry out additional studies using purified $\mathrm{T}$ subsets from thyroidal infiltrates from patients with Graves' disease and Hashimoto's thyroiditis and measure response in another way such as cytokine production or as numbers (\%) of CD154 positive cells which are induced following stimulation by specific antigen [27]. These methods are currently being set up in out laboratory.

\section{CONFLICT OF INTEREST}

The authors confirm that this article content has no conflicts of interest.

\section{ACKNOWLEDGEMENTS}

This research was supported by a Cy-Pres Award, Toronto, Canada and by a grant from Sydney West Area Health Service (Nepean Hospital). We thank Dr BA Ackrell (UCSF) for supplying recombinant Fp and Dr. Nicole Beard (The John Curtin School of Medical Research, ACT Australia) for supplying rabbit skeletal muscle calsequestrin.

\section{DISCLOSURE}

Part of the information included in this article has been previously published in Autoimmunity 2008, Vol. 41, No. 5, Pages 372-376.

\section{REFERENCES}

[1] Tunbridge WM, Evered DC, Hall R, et al. The spectrum of thyroid disease in a community: the Wickham survey. Clin Endocrinol 1977; 7: 481-93.

[2] Manji N, Carr-Smith JD, Boelaert K, et al. Influences of Age, Gender, Smoking, and family History on Autoimmune Thyroid Disease Phenotype. J Clin Endocrinol Metab 2006; 91: 4873-80.

[3] Lahooti H, Parmar KR, Wall JR. Pathogenesis of Thyroid Eye Disease: important role of autoimmunity against calsequestrin and collagen XIII: pathogenesis of Thyroid Eye Disease: important role of autoimmunity against calsequestrin and collagen XIII. Clin Ophthalmol 2010; 14: 417-25.

[4] Tjiang H, Lahooti H, McCorquodale T, Wall JR. Eye and eyelid abnormalities are common in patients with Hashimoto's thyroiditis. Thyroid 2010; 20: 287-90.

[5] Gopinath B, Adams CL, Musselman R, Tani J, Wall JR. Antibodies against calsequestrin and type XIII collagen are good markers for chronic upper eyelid retraction. Ocul Immunol Inflamm 2007; 15: 81-8.

[6] Bahn RS. Clinical review 157: Pathophysiology of Graves' ophthalmopathy: the cycle of disease. J Clin Endocrinol Metab 2003; 88: 1939-46. 
[7] Paschke R, Vassart G, Ludgate M. Current evidence for and against the TSH receptor being the common antigen in Graves' disease and thyroid associated ophthalmopathy. Clin Endocrinol (Oxf) 1995; 42: 565-9.

[8] Gopinath B, Musselman R, Beard N, et al. Antibodies targeting the calcium binding skeletal muscle protein calsequestrin are specific markers of ophthalmopathy and sensitive indicators of ocular myopathy in patients with Graves' disease. Clin Exp Immunol 2006; 145: 56-62.

[9] Gopinath B, Musselman R, Adams C, Tani J, Beard N, Wall JR. Study of serum antibodies against three eye muscle antigens and the connective tissue antigen collagen XIII in patients with Graves' disease with and without ophthalmopathy: Correlation with clinical features. Thyroid 2006; 16: 967-74.

[10] Bindra A, Braunstein GD. Thyroiditis. Am Fam Physician 2006; 73: $1769-76$

[11] Lazarus JH. Silent thyroiditis and sub acute thyroiditis. $7^{\text {th }}$ ed. Philadelphia: J.B. Lippincott 1996; p. 577.

[12] Wall JR. The TSH-Receptor and Thyroid-Associated Ophthalmopathy-a Convenient Hypothesis with too many exceptions to be true. Int J Endocrinol Metab 2007; 2: 49-51.

[13] Amato G, Rotondi M, Salzano I, et al. Extraocular muscle antibodies positivity as the only serum marker of euthyroid Graves' ophthalmopathy following sub acute thyroiditis: case report. J Clin Endocrinol Metab 2000; 85: 950-2.

[14] Gopinath B, Ma G, Wall JR. Eye signs and serum eye muscle and collagen XIII antibodies in patients with transient and progressive thyroiditis. Thyroid 2007; 17:1-7.

[15] Nguyen B, Gopinath B, Tani J, Wescombe L, Wall JR. Peripheral blood T lymphocyte sensitization against calsequestrin and flavoprotein in patients with Graves' ophthalmopathy. Autoimmunity 2008; 41: 372-6.

[16] Pappa A, Lawson JM, Calder V, Fells P, Lightman S. T cells and fibroblasts in affected extraocular muscles in early and late thyroid associated ophthalmopathy. Br J Ophthalmol 2000; 84: 517-22.

[17] de Carli M, D'Elios MM, Mariotti S, et al. Cytolytic T cells with Th1-like cytokine profile predominate in retro orbital lymphocytic infiltrates of Graves' ophthalmopathy. J Clin Endocrinol Metab 1993; 177: 1120-4.

[18] Nunery WR, Martin RT, Heinz GW, Gavin TJ. The association of cigarette smoking with clinical subtypes of ophthalmic Graves' disease. Ophthal Plast Reconstr Surg 1993; 9: 77-882.

[19] Mourits MP, Koornneef L, Wiersinga WM, Prummel MF, Berghout A, van der Gaag R. Clinical criteria for the assessment of disease activity in Graves' ophthalmopathy: a novel approach. Br J Ophthalmol 1989; 73: 639-44.

[20] Werner SC Classification of the eye changes of Graves' disease. Am J Ophthalmol 1969; 68: 646-8.

[21] Tani J, Gopinath B, Nuygen B, Wall JR. Immunological mechanisms for the eye muscle and orbital connective tissue reactions of thyroid-associated ophthalmopathy. Expert Rev Clin Immunol 2007; 3: 299-311.

[22] Gunji K, De Bellis A, Li AW, et al. Cloning and characterization of the novel thyroid and eye muscle shared protein G2s: autoantibodies against G2s are closely associated with ophthalmopathy in patients with Graves' hyperthyroidism. J Clin Endocrinol Metab 2000; 85: 1641-7.

[23] Salvi M, Miller A, Wall JR. Human orbital tissue and thyroid membranes express a $64-\mathrm{kDa}$ protein, which is recognized by autoantibodies in the serum of patients with thyroid-associated ophthalmopathy. FEBS Lett 1988; 232: 135-9.

[24] Porter JD, Khanna S, Kaminski HJ, et al. Extraocular muscle is defined by a fundamentally distinct gene expression profile. Proc Natl Acad Sci USA 2001; 98: 12062-7.

[25] De Haan, S, Lahooti H, Morris O, Wall J. Epitopes, immunoglobulin classes and immunoglobulin $\mathrm{G}$ subclasses of calsequestrin antibodies in patients with thyroid eye disease. Autoimmunity 2010; 43: 698-703.

[26] DeBellis A, Sansone D, Coronella C, et al. Serum antibodies to collagen XIII: a further good marker of active Graves' ophthalmopathy. Clin Endocrinol 2005; 62: 24-9.

[27] Frentsch M, Arbach O, Kirchhoff K, et al. Direct access to CD4+ $\mathrm{T}$ cells specific for defined antigens according to CD154 expression. Nat Med 2005; 11: 1118-24.

(C) Nguyen et al.; Licensee Bentham Open.

This is an open access article licensed under the terms of the Creative Commons Attribution Non-Commercial License (http://creativecommons.org/licenses/by-nc/3.0/) which permits unrestricted, non-commercial use, distribution and reproduction in any medium, provided the work is properly cited. 